posts in psychiatry, which are urgently needed for consultant vacancies.

Dr Azuonye also discusses locum consultant positions in psychiatry. Ideally, every locum consultant should be eligible for a substantive consultant post, that is, the doctor concerned should have passed the MRCPsych examination and completed higher training in psychiatry. Unfortunately at the moment many Health Authorities are appointing as locum consultants in psychiatry people who have not completed the necessary requirements. The reason they are doing so is, of course, because we have an inadequate number of senior registrar posts and therefore an inadequate number of trained senior registrars for consultant vacancies. Once again the solution to this difficulty is the establishment of more senior registrar posts.

It is difficult to see how the suggestion of replacing interviews between training grades in psychiatry with examinations will achieve any real benefit. It would be highly disadvantageous to training to continue with examinations throughout a six year period. It would have a disastrous effect upon psychiatric research at a trainee level at a time when people are potentially very creative. It would also be highly disadvantageous for trainees in specialties such as child and adolescent psychiatry, who instead of being able to enter their chosen specialty after three years in psychiatry, would be prevented from so doing until completion of six years experience.

Finally, Dr Azuonye claims that his model would prevent "such a thing as time expired senior registrars". There are no time expired senior registrars at the moment. In fact the concern is that trainees move out of senior registrar into consultant post too quickly because of the shortage of trained senior registrars.

A. C. P. Sims

Dean (July 1987-July 1990)

\title{
Emergency and liaison psychiatry
}

\author{
Alison Gourdie; Registrar; and ViviEnNe SCHNIEDEN, Registrar, Department of \\ Psychological Medicine, Accident and Outpatient Building, University College \\ Hospital, Grafton Way, Gower Street, London WC1E 6AU
}

\section{Background}

The post of Emergency and Liaison Registrar in the Bloomsbury Rotation was created in 1988 to provide a psychiatric service at University College Hospital, London, in the Accident and Emergency (A\&E) Department and to the A\&E Ward for assessment of deliberate self harm (DSH) cases. It incorporated existing commitments of liaison to the $\mathrm{UCH}$ wards and provision of urgent psychiatric assessments. The service had previously been shared among a number of psychiatric staff. The registrar can thus be seen as a 'central pivot' within the District Psychiatric Services.

The Bloomsbury Health Authority provides health care in an inner city district. The resident population is approximately 135,000 and in the daytime is increased considerably by visitors and commuters. The composition of the resident population is diverse, multi- racial, contains a wide spread of social classes and a large number of single person households. An important determinant of the district's composition is its high proportion of homeless persons. This is related to a number of factors; for example, there are three major railway stations within the district (daily passenger numbers exceed 150,000), and a large number of DSS bed \& breakfast hotels.

\section{Description}

We saw 325 new cases over one year. These consisted of: A\&E 101; DSH 99; general practitioner referrals 69; liaison cases 56.

The commonest reasons for referral from the A\&E Department were: assessment of suicide risk $45.7 \%$, bizarre behaviour $32.6 \%$, recent relapse $15.2 \%$. The A\&E cases necessitated immediate assessment due 
to extremely disturbed behaviour and two-thirds of these required in-patient admission.

Current hospital policy is that all admitted cases of DSH are referred for psychiatric assessment; $10 \%$ were transferred to the psychiatric wards, the rest were offered out-patient care, other district services or referred back to the GP.

The GP referrals were variable in both urgency, presenting problems, and appropriateness. The most common requests were: assessment of bizarre behaviour $23.7 \%$, recent relapse $18.4 \%$, not responding to treatment $15.8 \%$, and suicide risk $13.2 \%$. GP referrals were either seen immediately or deferred to one of the registrar's out-patient clinics held within the next week.

Supervision evolved over the year to fit in with the perceived needs and was provided by a consultant and senior registrar and psychoanalyst. A social worker was available for consultation and referral.

\section{Comment}

Historically there has been a strong interest in psychosomatic medicine at UCH. Only a minority of training schemes have specific posts in liaison psychiatry (Mayou \& Lloyd, 1985) but recently increasing attention has been given to this area. The Liaison/ Psychiatry Group drew up guidelines for training (Royal College of Psychiatrists, 1988) and in this job the experiences obtained were broad and covered the areas outlined by the Committee; in particular, skills for the assessment of suicide risk, DSH cases, and management of patients on medical and surgical wards. The job is broader than traditional liaison psychiatry because of the DSH assessment.

One criticism may be that there was inadequate time to follow up cases. This may have been detrimental to patients, as follow up with the initial contact person during a crisis has been shown to be an important predictor of engagement in DSH.

During the year we developed a strong relationship with the A\&E Ward as a result of the number of DSH cases seen there. We therefore received a small number of cases referred by nursing staff who recognised an element of DSH in a patient's presentation missed by the medical team. It is important to be open to new methods of referral as these are often as appropriate as strictly medical referrals (Sensky et al,
1985). Liaison psychiatrists who restrict themselves to identifying psychiatric illness may miss the purpose of the liaison consultation, that is to help his non-psychiatric colleagues uncover relevant psychological or social aspects and to identify and deal with the patient's reaction to his physical illness (Wolff, 1990).

The service and experience of the trainee could be improved by a multidisciplinary approach. Trained nurses, junior medical staff or social workers can provide comparable assessment to junior registrars in DSH cases, and a full time liaison nurse could prove invaluable to the service (Hicks, 1989) and result in fewer referrals and management difficulties on the wards.

Due to the busy nature of the job and demands on the individual registrar's emotional and personal resources, and the essentially solitary nature of the work, six months would seem an optimum time period. The job provides ample opportunities and ideas for research and an invaluable experience in emergency psychiatry.

\section{Acknowledgement}

We would like to thank Dr Sturgeon and all the staff in the department for their support and encouragement.

\section{References}

Hicks, S. (1989) The psychiatric nurse in liaison psychiatry. Australian and New Zealand Journal of Psychiatry, 23, 89-96.

MAYOU, R. \& LLOYD, G. (1985) A survey of liaison psychiatry in the United Kingdom and Eire. Bulletin of the Royal College of Psychiatrists, 9, 214-217.

Royal College of Psychiatrists Executive Committee OF THE Liaison PSYCHIATRY GrouP (1988) Guidelines for Training in Liaison Psychiatry. Psychiatric Bulletin, 12, 389-390.

Sensky, T., Greer, S., Cundy, T. \& Pettingale, $\mathrm{K}$. (1985) Referrals to psychiatrists in a general hospital comparison of two methods of liaison psychiatry: Preliminary communication. Journal of Royal Society of Medicine, 78, 463-468.

Wolff, H., Bateman, A. \& Sturgeon, D. (1990) UCH Textbook of Psychiatry. London: Duckworth.

A full list of references is available on request to the authors. 